\title{
Economic globalization, nutrition and health: a review of quantitative evidence
}

\author{
Soledad Cuevas García-Dorado ${ }^{2,4^{*}}$ (D), Laura Cornselsen ${ }^{1,2}$, Richard Smith ${ }^{3}$ and Helen Walls ${ }^{1,2}$
}

\begin{abstract}
Background: Unhealthy dietary patterns have in recent decades contributed to an endemic-level burden from non-communicable disease (NCDs) in high-income countries. In low- and middle-income countries rapid changes in diets are also increasingly linked to malnutrition in all its forms as persistent undernutrition and micronutrient deficiencies continue to coexist with a rising prevalence of obesity and associated NCDs. Economic globalization and trade liberalization have been identified as potentially important factors driving these trends, but the mechanisms, pathways and actual impact are subject to continued debate.

Methods: We use a 'rigorous review' to synthesize evidence from empirical quantitative studies analysing the links between economic globalization processes and nutritional outcomes, with a focus on impact as well as improving the understanding of the main underlying mechanisms and their interactions.

Findings: While the literature remains mixed regarding the impacts of overall globalization, trade liberalization or economic globalization on nutritional outcomes, it is possible to identify different patterns of association and impact across specific sub-components of globalization processes. Although results depend on the context and methods of analysis, foreign direct investment (FDI) appears to be more clearly associated with increases in overnutrition and NCD prevalence than to changes in undernutrition. Existing evidence does not clearly show associations between trade liberalization and NCD prevalence, but there is some evidence of a broad association with improved dietary quality and reductions in undernutrition. Socio-cultural aspects of globalization appear to play an important yet under-studied role, with potential associations with increased prevalence of overweight and obesity. The limited evidence available also suggests that the association between trade liberalization or globalization and nutritional outcomes might differ substantially across population sub-groups.

Overall, our findings suggest that policymakers do not necessarily face a trade-off when considering the implications of trade or economic liberalization for malnutrition in all its forms. On the contrary, a combination of nutrition-sensitive trade policy and adequate regulation of FDI could help reduce all forms of malnutrition. In the context of trade negotiations and agreements it is fundamental, therefore, to protect the policy space for governments to adopt nutrition-sensitive interventions.
\end{abstract}

Keywords: Globalization, Trade liberalization, FDI, Nutrition transition, Non-communicable disease

\section{Introduction}

International trade as a proportion of global GDP has almost doubled since the beginning of the 1970s, and now represents almost $60 \%$ of world GDP [1]. This increased exchange of goods and services has occurred as part of a wider process of globalization, encompassing inter-related

\footnotetext{
* Correspondence: soledad.cuevas@soas.ac.uk

${ }^{2}$ Leverhulme Centre for Integrate Research on Agriculture and Health, 36 Gordon Square, London WC1H OPD, UK

${ }^{4}$ SOAS, University of London, Bloomsbury, London WC1H OXG, UK Full list of author information is available at the end of the article
}

economic, social and cultural components [2]. Trade policies and globalization processes are deeply transforming societies, shaping political institutions, economic and social relationships, modes of production, consumption patterns and lifestyles. These structural factors are increasingly recognized as important drivers of nutrition and health outcomes [3-5]. In particular, trade reforms and liberalization have often been linked to both under-nutrition and the rapid rise in overweight and obesity and spread of diet-related non-communicable diseases (NCDs) in low- and middle-income countries (LMICs) 
$[6,7]$. Traditionally considered a problem of high-income countries, the burden of overweight, obesity and diet-related NCDs has in recent years greatly increased in LMICs, which already account for more than $80 \%$ of deaths from NCDs worldwide [8]. Increased prevalence of overweight, obesity and NCDs, however, often coexists with persistent undernutrition and micronutrient deficiency, leading to what is known as a double (or triple) burden of malnutrition [9].

Debate on the links between trade liberalization and nutrition can be traced back to the controversial implementation of structural adjustment programmes by the World Bank and International Monetary Fund (IMF) in the 1980s $[10,11]$. Following the international food crisis in 2008 and in the context of the growing obesity "epidemic", however, this issue has gained renewed attention from researchers and policy-makers. This has led to the recent surge of publications that approach the issue, and increasingly so from different angles, providing new and updated evidence on the subject.

Several recent reviews have mapped the pathways between trade agreements and food-related aspects of public health, including related to food environments [12], and the nutrition transition [13]. Studies have synthesized existing evidence of the impacts of agricultural trade liberalization on food security in LMICs [14], and analysed the effect of trade and investment liberalization on prevalence of NCDs in Asia [15]. There is a wide variation in terms of quality and design of the studies included in these reviews, ranging from case-studies to quantitative multi-country and natural experimental designs. In addition, Barlow et al. [16] recently published a more general review of quantitative studies analysing the impact of regional trade agreements on major health risk factors and outcomes, including some evidence on nutrition-related outcomes.

To our knowledge, however, there has not been a systematic analysis and synthesis of the empirical evidence on the associations between economic globalization and liberalization processes and nutrition outcomes. This review complements the existing evidence, through the use of a 'rigorous review' methodology as described by Hagen-Zanker and Mallett [17] to undertake analysis of studies quantifying the relationship between economic globalization and nutritional outcomes including under and overnutrition and incorporating new, relevant evidence not covered by previous reviews. The specific focus on malnutrition in all its forms is in line with recent literature calling for integrated approaches to address the growing double (or triple) burden of malnutrition $[18,19]$. Malnutrition in all its forms is understood to include undernutrition, micronutrient deficiencies, overweight and obesity and related NCDs [20]. This approach allows us also to explore evidence of the overlapping processes of dietary convergence-divergence that take place as food systems become increasingly integrated.

\section{Conceptual framework}

Jenkins (2004) describes globalization as "a process of greater integration within the world economy, through movements of goods and services, capital, technology and (to a lesser extent) labour, which leads increasingly to economic decisions being influenced by global conditions" [21]. This definition focuses on economic globalization, concerned with changes taking place to world trade and investment, but adopting the view that economic forces underlie and shape the overall globalization process, connecting what are sometimes described as different aspects of globalization, including socio-cultural changes and information flows [2].

We have developed a framework, shown in Fig. 1, to conceptualise the relationships between globalization, nutrition and related health outcomes. The framework, informed by existing theoretical works and published conceptual frameworks, $([2,4,6,12,22])$ includes the main sub-components of globalization and the trade and investment policies underpinning the process. It depicts the impact of globalization processes on nutrition outcomes as linked through changes in food systems and food environments, as well as through impacts on national policy and regulatory space, and through the transformation of broader socio-economic factors. Socio-economic factors also play an important role as mediators of the effect of food environment changes, resulting in heterogeneous effects across population sub-groups. Before proceeding to a description of the method used and our study findings, we will briefly describe each of the domains in Fig. 1, as they relate to the wider framework.

\section{International trade and food environments}

This pathway is shown at the top and to the right in our conceptual framework. International trade is generally understood to encompass the exchange of both goods and services across countries. Although most of the papers included in this review tend to focus their discussion on trade in goods rather than services, perhaps implicitly assuming more relevant linkages between trade in goods and dietary and nutrition outcomes, many use composite indices that include trade in services, such as the economic component of the KOF index for globalization or its sub-components. ${ }^{1}$

The creation of a global market for food products has important effects on the availability and prices of food commodities. On the production side, global markets encourage specialization in export crops, which tends to create economies of scale in agricultural and food production, leading to increased global output, but also to 


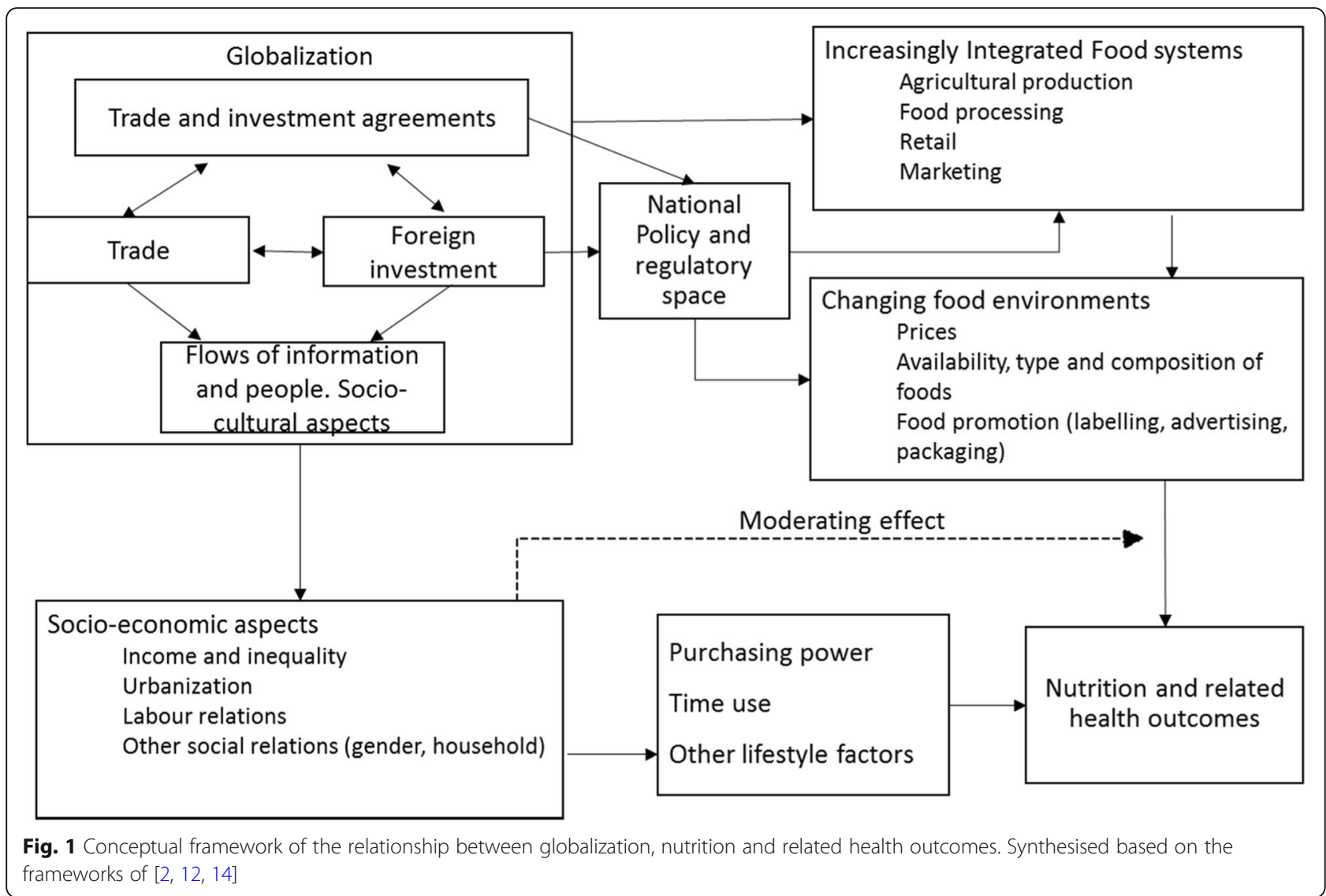

homogenization in the availability of food products $[7,23,24]$. On the demand side, countries can increase their access to a variety of goods through imports, including essential foodstuffs [25] and healthy foods [26] as well as potentially unhealthy processed and ultra-processed products [27, 28]. The relationship between international trade and food prices is complex. Access to international commodity markets can reduce food price volatility by diminishing the effect of local shocks. However, it increases the exposure to global demand instability, as well as to volatility in the "terms of trade" for highly specialized countries [29]. On average, trade openness has been found to lower the relative price of calorie-dense foods and animal feed [30].

\section{Foreign direct investment}

Foreign direct investment (FDI) is an investment by which a foreign company acquires control over a (new or pre-existing) business. This is to distinguish FDI from portfolio investments where investors are not involved in or have control over the day to day operations of a business [31] Like trade, FDI is also thought to play an important role in transforming food systems. It is FDI, rather than trade, that is considered to be the currently preferred method for Transnational Food Companies
(TFC) to enter new markets for processed foods, allowing multinationals to advertise and market their products more efficiently, creating a demand while, simultaneously, adapting to consumer characteristics [32].

Both FDI and advertising are also thought to lead to indirect effects on nutrition; increasing competition among local firms and increasing the demand not only for the marketed brand, but for the whole category, be it snacks, ice-cream or "diet" and "wellness" products [6]. Additionally, retail and marketing strategies contribute to market segmentation, which is believed to lead to a divergence in dietary patterns within countries, even as diets converge across countries. [6, 33, 34].

\section{Sociocultural aspects of globalization}

Increased global flows of information (and people) can transform cultural norms, social relations, and consumption patterns. The spread of communication technology and infrastructure makes it possible for information to be shared more widely and faster, but it does not in itself explain the content, influence and directionality of the information exchange. These are thought to be driven by economic forces operating through the expansion of large multinationals in media, communications and marketing [35]. The globalization of marketing and 
promotion, aided by the expansion of TFC and global marketing companies, are thought to play an important role in the integration of food markets, changing consumption patterns, and creation of a demand for new products and brands [36].

\section{Policy and regulatory space}

The creation of progressively integrated global markets is underpinned by trade and investment agreements and policies. The World Trade Organization (WTO) remains the main international organization responsible for the global rules of trade between countries. ${ }^{2}$ Since the early 1990s however, an increasing number of regional and bilateral trade agreements have been negotiated outside of the WTO system. ${ }^{3}$ These agreements frequently reflect power imbalances between participating countries, can be heavily influenced by the interests of multinational companies and can have deep impacts on domestic policy [37, 38]. The inclusion of mechanisms for investor-state dispute settlement, whereby companies can directly sue states, is an example of the new ways in which this "new generation" of agreements can reduce the capacity of governments to implement health-oriented regulation that might lead to reduced profits for foreign investors $[15,39,40]$. Some authors have specifically argued that trade and investment agreements can negatively affect nutritional outcomes by directly reducing the regulatory and policy space for health-promoting initiatives $[40,41]$. We have found a small number of studies that quantitatively analysed aspects of political globalization alongside measures of economic dimensions. However, these are very partial and non-specific measures of the potential impacts of trade agreements on the policy space. It is important to bear in mind that some of the most influential literature on this topic $[39,41]$ is qualitative and was not included in this review as our focus is specifically on quantitative studies. This literature, however, does suggest that the impact of restrictions to the policy space, associated with trade liberalization processes, should not be underestimated, as it can curtail the capacity of governments to protect public health [42].

\section{Interaction with socioeconomic drivers of nutrition}

Market integration and trade and investment agreements not only affect nutrition outcomes through their impacts on the food sector. Globalization processes deeply transform all aspects of society, in ways which can indirectly affect nutrition outcomes. Globalization has been found to be associated with GDP and income growth [43, 44], but also to increased income inequality [45], as well as to [46] urbanization [47, 48]. According to some authors, globalization has also been associated with a deterioration in labour standards and conditions [49], coupled with a transition towards sedentary and "knowledge-based" work [50] while, for others, integration in the global economy increases the returns to labour, encouraging larger investments in health [51]. Although some mechanisms are better understood than others, all of these structural socioeconomic changes have been linked to changes in dietary patterns and should be taken into account when assessing the links between globalization and nutrition outcomes.

\section{Methods}

\section{Methodological approach}

Systematic review methods have recently been subject to criticism regarding their inflexible application to social sciences. Critics have pointed out the considerable degree of subjectivity in the interpretation, definition and use of concepts in social sciences, as well as the importance of context, which is often ignored in traditional systematic reviews $[17,52]$. Similar arguments have been made specifically concerning reviews in public health $[53,54]$. Considering this, we undertook a 'rigorous review', following the core principles listed in Hagen-Zanker and Mallet [17] as guidance on conducting rigorous, evidence-focused literature reviews in international development. Thus, we adhered to the principles of rigour, transparency and replicability at the core of the systematic literature review process, but followed a process that also allows for flexibility and reflexivity [17] . Importantly, in our analysis we acknowledge the subjectivity in interpretation of concepts and thus emphasise the importance of context in the interpretation of the studies and their significance for policy-making. Furthermore, our focus is on "how" social change works, rather than on "what" the impact of any policy or process is.

The rigorous review approach has also allowed us to classify the included articles according to relevant criteria (see Table 2), facilitating a structured analysis and discussion of the findings in the literature.

\section{Search}

We searched for studies containing terms related to economic globalization, trade and investment liberalization, food and food environments, and nutrition and related health outcomes as well as terms related to quantitative research methods. We conducted this search in five databases (Web of Science, Scopus, Global Health, EconLit and MEDLINE) and several institutional websites, including WHO, WTO, UNCTAD, IFPRI and USAID. We complemented this with a general search on Google and Google Scholar. Searches were carried out in March-2017. We checked the reference lists of articles selected for full text review for further relevant publications.

The references were screened by two authors and any disagreements were resolved through discussion. In the 
first round of screening, potentially relevant articles were selected based on the general focus of the study as judged by the title and abstract. In the second round, relevant references were screened based on inclusion criteria, described in Table 1. Figure 2 shows the document flow and the number of references retrieved in the different stages of the search and screening process [6]. An additional Contains assessment criteria provides further detail of the search strategy [see Additional file 1].

\section{Inclusion criteria}

Detailed explanation of inclusion criteria is provided in Table 1. The criteria take into account the overall focus of the paper, methods, definition of globalization and nutrition outcomes, and the year and language of the publication.

\section{Information extraction and analysis}

Articles meeting the inclusion criteria were recorded in an Excel database including key information on context (country, time frame), globalization processes observed

\section{Table 1 Inclusion criteria}

\begin{abstract}
Focus
Includes: Studies that retrospectively analyse the impacts of economic globalization processes on nutrition and related health outcomes, both in high, medium and low income countries.
\end{abstract}

\section{Methods}

Includes: Quantitative, empirical studies that analyse associations between economic globalization and nutrition and related health outcomes (e.g. multi-country regression analysis controlling for covariates or country heterogeneity, multi-level regression, quasi-experimental designs, time series analysis).

Excludes: Prospective simulation based analysis, qualitative studies, studies that use quantitative information descriptively, without statistical analysis.

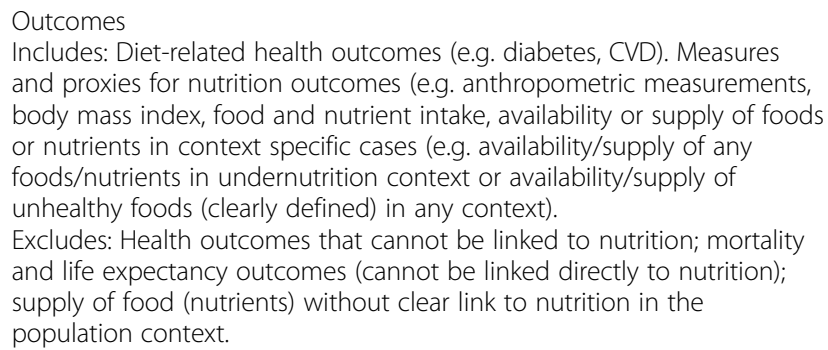
investment agreements or policies, trade openness; measures of economic globalization. We do not include studies that focus exclusively on global flows of information, social or cultural globalization. Excludes: Studies analysing the impacts of policies or agreements that might be affected by trade negotiations (e.g. national agricultural or monetary policy); impact of measures introduced to counteract the effects of trade liberalization, such as export bans. (including definitions of the processes), type and source of data analysed, statistical methods applied, and main findings and conclusions from the study. The analysis of the studies included examining findings against existing conceptual frameworks and theoretical evidence, as well as with the findings of previous reviews on similar topics.

\section{Results}

Seven hundred fourteen articles were identified from five different databases, another 64 were retrieved from institutional websites, and 16 from additional searches on Google or Google scholar. The abstracts of all studies were screened and the full texts of 63 studies which were found to be relevant were downloaded for screening. 24 of these met our inclusion criteria. In addition, four relevant review studies were identified.

Of the 24 articles included, 11 look at diet-related health outcomes or biomarkers, including underweight, overweight, obesity, diabetes, CVD prevalence and BMI. A further 13 articles used context-relevant proxies of nutrition outcomes, including energy ( $\mathrm{kcal}$ ) intake per day, dietary diversity, and markers of dietary quality such as consumption of unhealthy food commodities, fat intake, consumption of protein and animal protein. Half of the studies (12 out of 24) focussed on LMICs. Most studies used country level data, while only three studies used multi-level models to account for effects occurring at different levels of aggregation. Natural experiments or difference-in-difference designs were used in three studies, and one study relied on single-country time series data. Two studies used less conventional approaches such as non-parametric correlation or structural equation modelling. Details of variables used, study design, data sources and main findings are provided in Table 2.

Given the complex nature of the topic and the intrinsic impossibility in carrying out intervention studies, we found that rating the quality of studies was not only extremely difficult but also potentially risked over-simplification. For this reason, we have provided a methods assessment using five criteria (see Additional file 2: Type of evidence). It should be noted, however, that in this context, different types of study can provide complementary evidence, and that this classification reflects different 'types of evidence', rather than overall quality.

We present the results following the structure of the framework (Fig. 1) concerning trade, investment, socioeconomic dimensions, such as global flows of information, and political aspects and their impacts on nutritional outcomes. We also comment on the differential results across population groups, defined by the main socioeconomic variables, which moderate the impacts of globalization.

\section{Economic globalization: Trade and investment}

Six of the studies reviewed used index measures of economic globalization [55-58] [51, 59], which include 


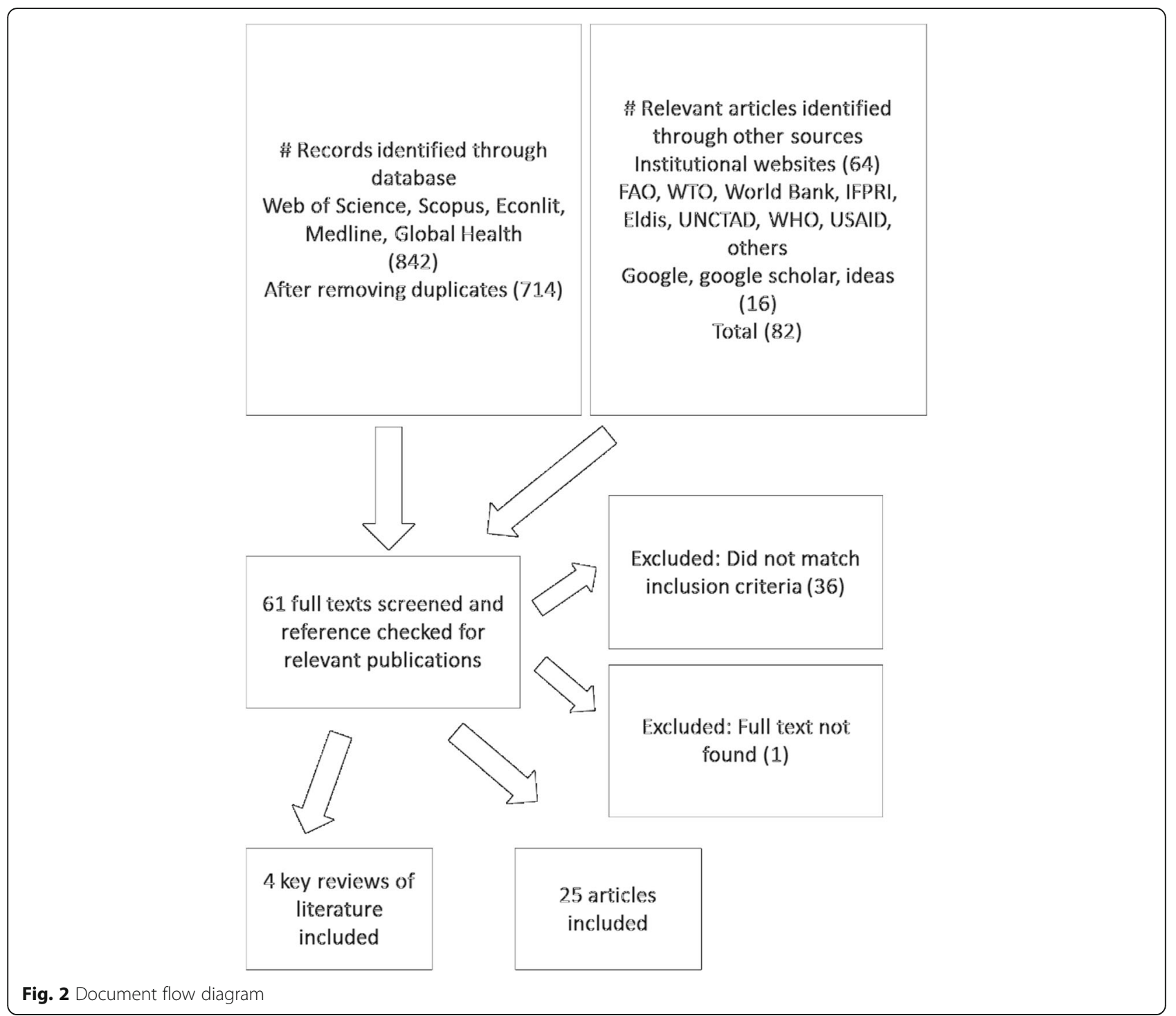

flows of goods, services and investment as well as barriers to trade and investment. Three of these studies find that economic globalization tends to reduce obesity and overweight $[51,55,56]$ as well as caloric and fat intakes [56] although the effects are small [55] or non-significant after controlling for additional variables such as urbanization, food prices, female participation in the workforce or number of McDonalds per capita [56], which can reflect potential confounding but might also be capturing partial impact mechanisms [55].

The remaining three studies find that economic globalization has a negative impact on nutrition-related health outcomes, leading to increased diabetes [57], overweight and obesity [59] and increased BMI [57, 58]. Oberlander et al. [57], find that, despite associations with diabetes prevalence and BMI, there seems to be no significant impact of economic globalization on dietary patterns.
The apparently contradictory findings can most likely be attributed to a certain extent to differences in the data. Oberlander et al. [57] use the longest time series, including data on 70 countries for 40 years, while de Soysa et al. [51] use the largest number of countries, including data on 180 countries for 23 years while Costa-i-Font et al. [55] include only higher income countries.

Moreover, studies differ in terms of the approach to estimation and methods chosen to deal with potential confounding effects. Schram et al. [59] use System Equations Modelling (SEM) to carry out pathway analysis on cross-sectional data, Costa-i-Font et al. [55] and de Soysa et al. [51] use panel corrected standard errors, which is a method to account for heteroskedasticity in time-series-cross-section data. Oberlander et al. [57], meanwhile, use group standard errors and a five-year lag on the main explanatory variables. Finally, while some key control variables such as income, inequality and 


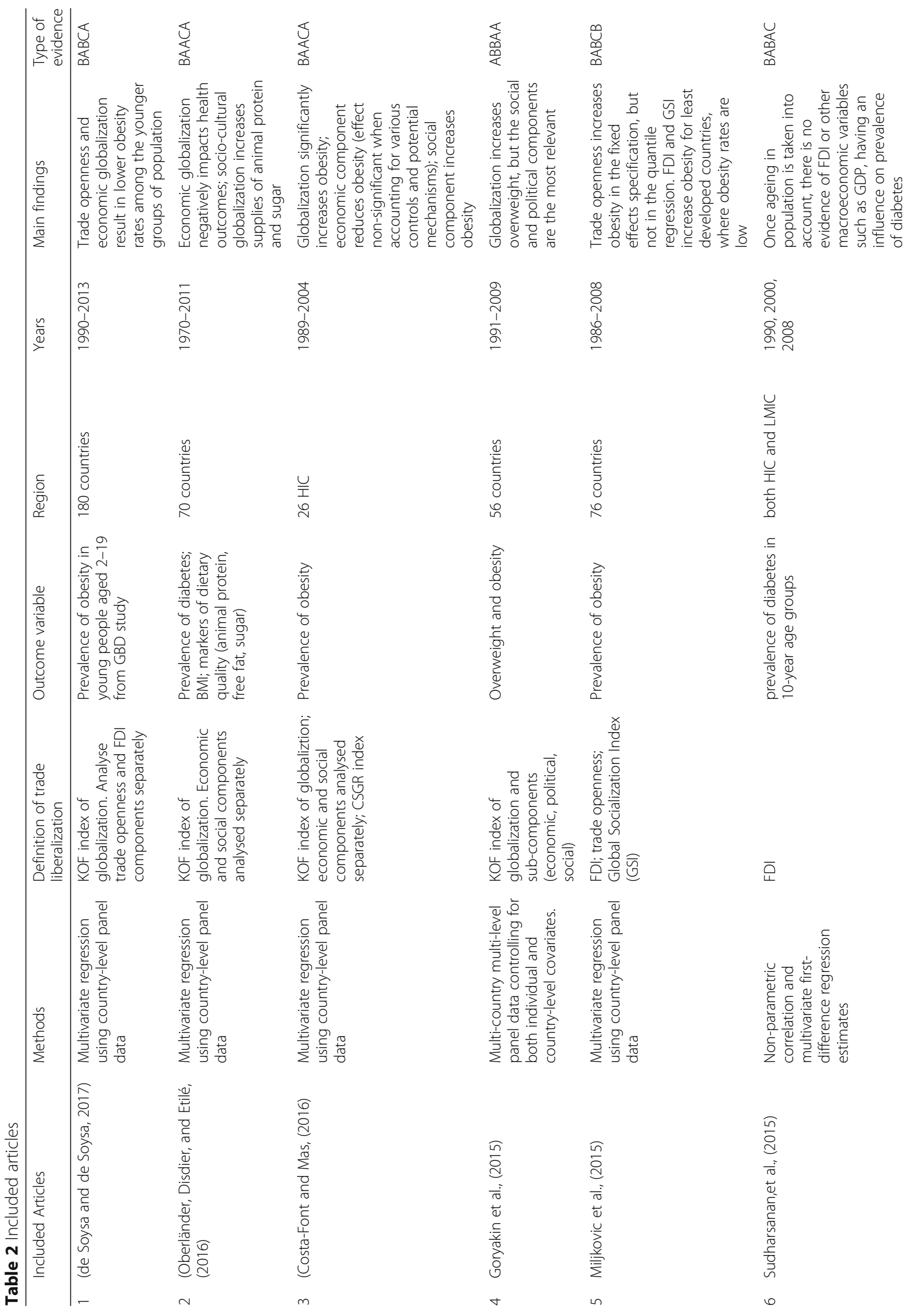




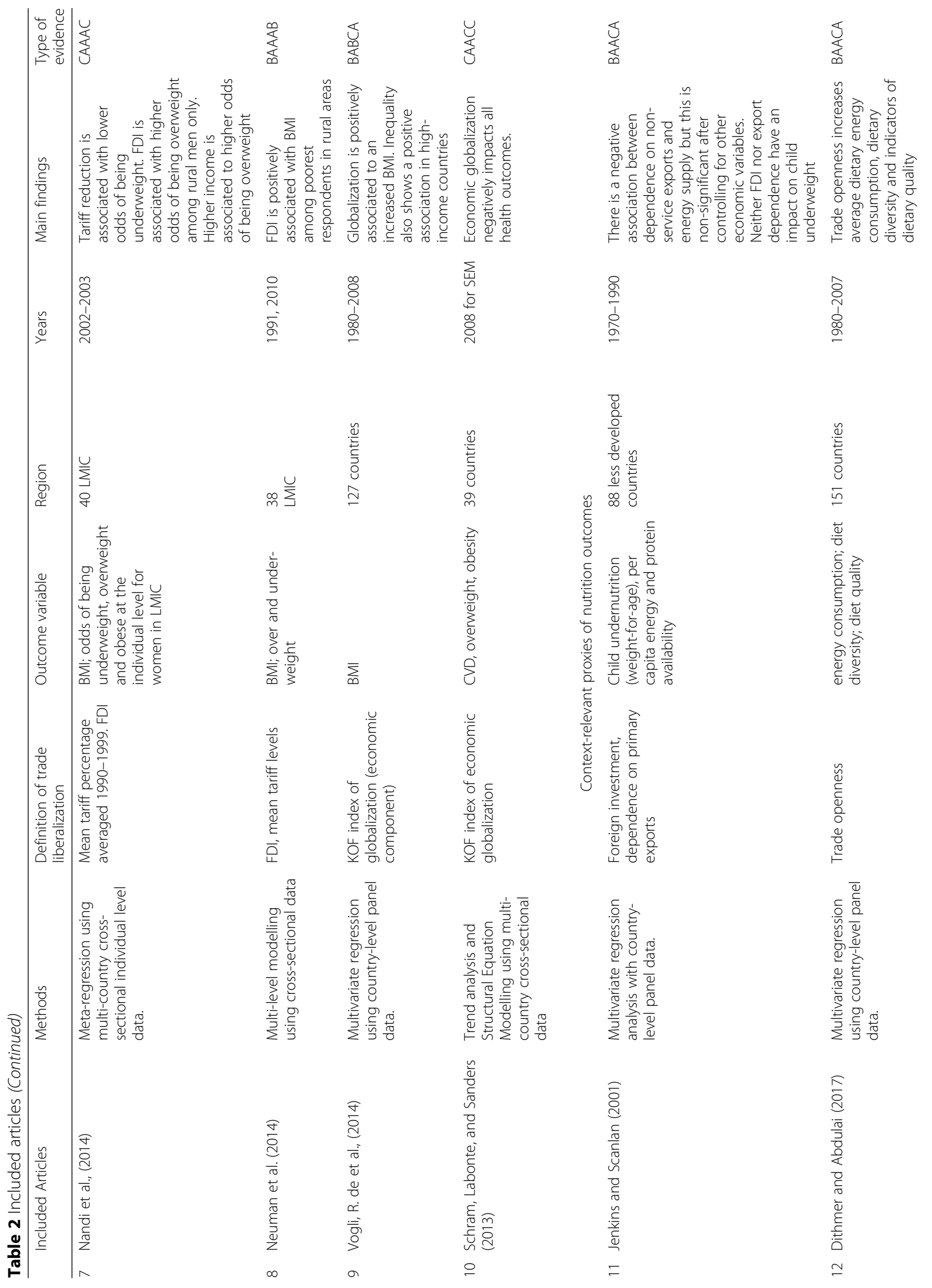




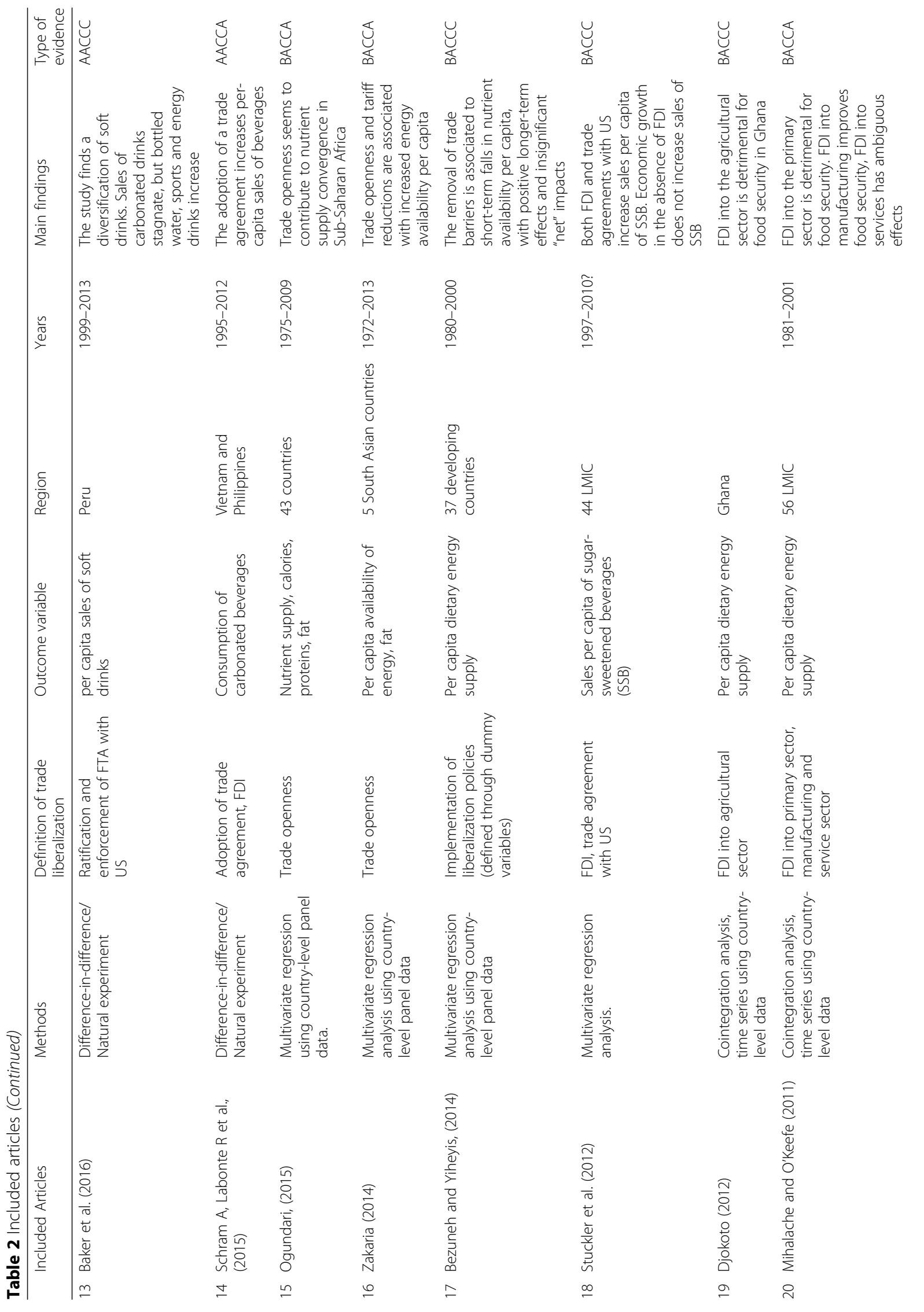




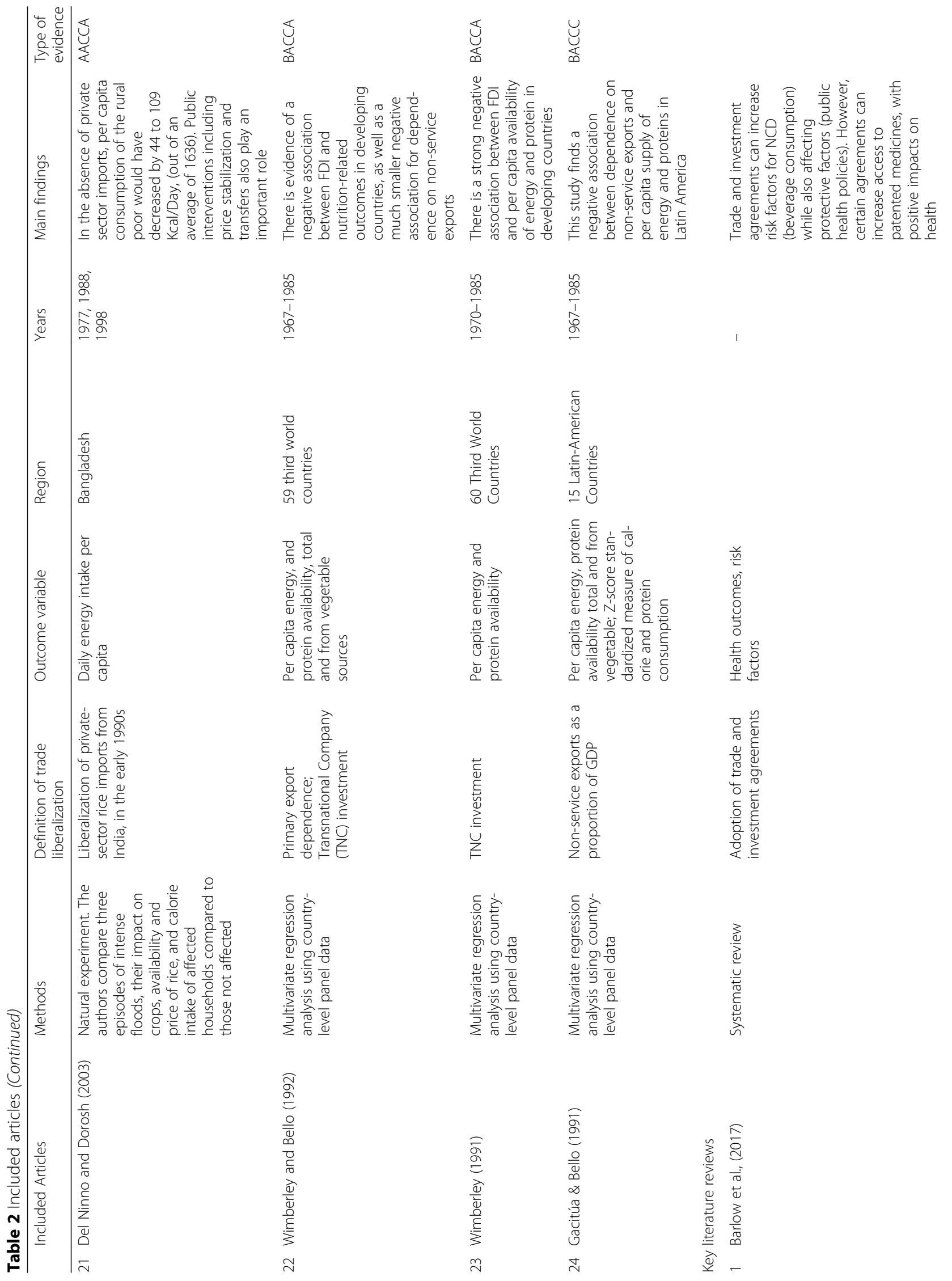


Cuevas García-Dorado et al. Globalization and Health

(2019) 15:15

Page 11 of 19

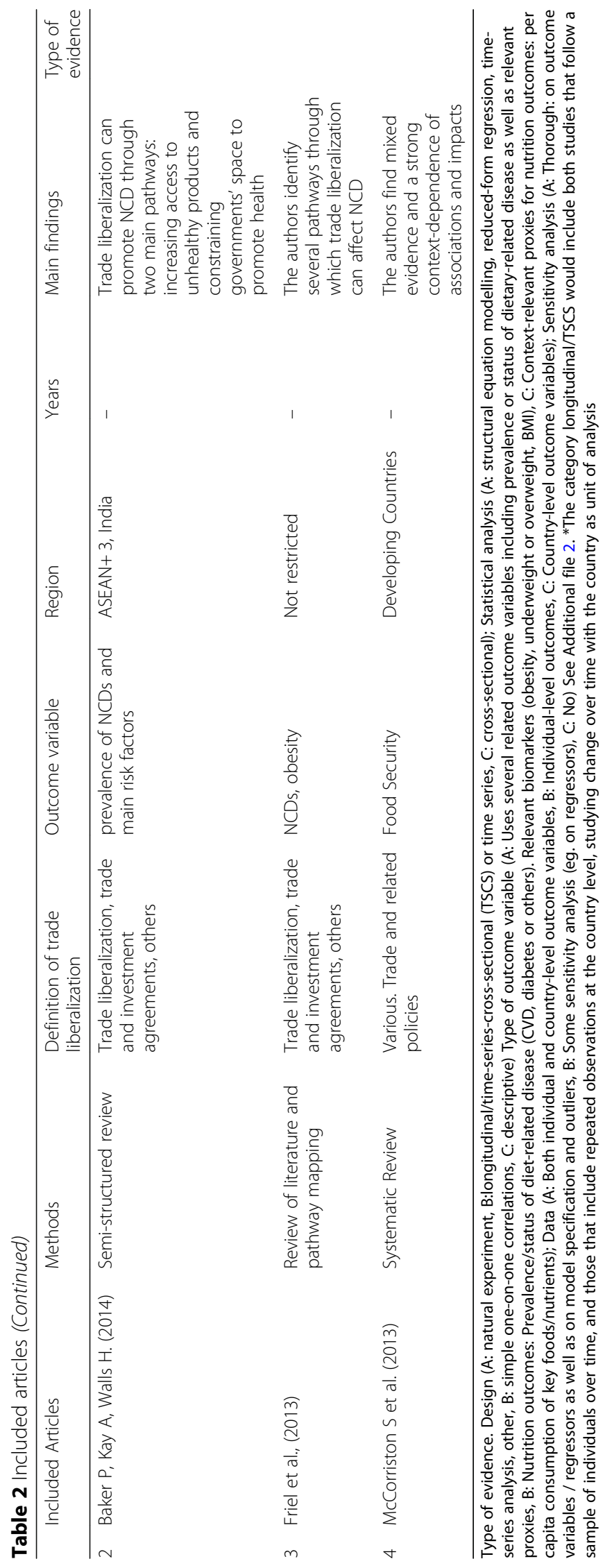


urbanization are included in all studies, there are differences in terms of additional control variables, which can modify the interpretation of results (for example, Schram et al. [59] account for tobacco consumption, while de Vogli et al. [58] control for poverty rates).

Overall, the results regarding economic globalization as a whole are inconclusive. The inconsistencies both across and within studies suggest that the association between economic globalization indices and nutritional outcomes is complex and easily confounded or captured by simpler variables. Studies looking at aggregate indices are relevant, however, in highlighting the importance of aspects of globalization not captured by the economic component of the index, including flows of information or political, policy and regulatory space, which we discuss in Section "Policy and regulatory space".

\section{Trade}

We identified 11 studies analysing the nutritional impacts of trade openness or reduction of trade barriers. Controlling for a wide range of variables including GDP, income levels, urbanization and other socioeconomic variables such as occupation and household structure, these studies find mixed results concerning undernutrition, with some recent evidence suggesting that trade openness might be associated with reductions in underweight and increases in nutrient supply and intake and various proxies for dietary quality. There is no convincing evidence linking trade openness to increased overweight, obesity or other measures of diet-related NCDs.

Three early studies based on country-level data found a negative association between dependence on non-service or primary exports and average per capita availability of calories and especially proteins in the Latin-American context [60] and for developing countries in general [61, 62]. This negative relationship was attributed partly to the restrictions to imports including quotas and other non-tariff barriers that frequently accompanied export-promotion policies [60]. These studies, however, found the impacts to be small compared to the effects of foreign investment [61] or insignificant after controlling for investment and other economic variables [62]. Moreover, Jenkins and Scanlan [62] found that dependence on primary exports had no impact on child underweight.

Six studies analysed the relationship between overall trade openness and dietary patterns, underweight or BMI. Bezuneh and Yiheyis [63] found that the removal of trade barriers was associated with short-term falls in nutrient availability per capita, with positive longer-term effects and insignificant "net" impacts. However, this study, is based on a relatively small sample, compared to more recent studies [64].

Del Ninno, Dorosh, and Smith [65] used a quasi-experimental approach, comparing three episodes of severe floods in Bangladesh. They found that, in the absence of private imports, per capita calorie intake of the rural poor would, measured at the household level, have decreased significantly due to scarcity and increased prices of rice. The authors find, however, that public interventions in price regulation and transfers also played an important role in mitigating hunger following natural disaster episodes.

Based on more recent data, three studies have found that trade openness and tariff reduction are associated with increased calorie availability per capita [66], improved aggregate indicators of dietary diversity and quality [64], and decreased odds of being underweight for both rural and urban men and women [67]. The latter study, however, is based on cross-sectional household-level data, so further research would be needed in order to determine whether this association might be causal. Neuman et al. [68], meanwhile, found no evidence of a significant association between mean tariff rates and mean BMI or underweight in a multi-level multi-country analysis of 30 LMIC, although they found that higher tariff rates were associated with lower BMI for poorer, rural populations.

Overall, neither trade as a proportion of GDP or tariff levels seem to be directly associated with increased prevalence of overweight, obesity or NCDs. In the study by Nandi et al. [67] the association between trade openness measured through tariff levels and overweight, unlike the association with underweight, was found to be insignificant. Miljkovic [69] report positive impacts of trade on obesity rates in a fixed-effects model controlling for country heterogeneity but not income, urbanization or inequality. The same study reports non-significant effects of trade openness on adult obesity rates at a country level using a quantile regression model. Perhaps more surprisingly, de Soysa and de Soysa [51] report a negative association between trade openness and rates of overweight for children and adolescents. The authors argue that if globalization increases the returns to labour this could increase the incentives to invest in children's health, leading to healthier diets and reduced levels of obesity and overweight.

\section{Foreign direct investment}

Overall, studies analysing the role of FDI suggest that FDI might be associated with an increased consumption of sugary and highly processed foods and increases in overweight and obesity in LMICs in particular. Four studies found positive associations with obesity, overweight or related dietary indicators, one found a positive association which was nevertheless not robust to changes in model specification [69], and three studies found non-significant associations.

Schram [70], using a natural experiment design, found a significant increase in sugar-sweetened beverages sales 
per capita, attributable to the removal of restrictions to FDI in Vietnam. Baker et al. [28] used a similar approach in Peru and found that following trade and investment liberalization that significantly increased FDI inflows, sales of carbonated drinks stagnated, while sales of juice, energy and sports drinks, as well as bottled water, increased. These more nuanced results emphasise the role of branding, diversification of branding and preference change, which can lead to changes in demand towards juice and sports drinks, which are often high in sugar and energy content, but marketed as healthy, potentially reaching a wider consumer base [71]. These findings corroborate previous research by Stuckler et al. [72] who showed that levels of FDI moderate the impact of GDP on consumption of unhealthy food products, including soft drinks, ice-cream, and confectionery, ultra-processed and packaged foods.

Miljkovic et al. [69] used a quantile regression specification with country-level panel data, finding that FDI was associated to increase obesity rates only in LMICs, although the association was insignificant in their fixed effects specification including all countries. In a multilevel analysis of adults in LMICs, Nandi et al. [67] found that FDI was associated to increased prevalence of overweight for rural men only. The same study found no association with prevalence of underweight.

However, Neuman et al. [68] and de Soysa and de Soysa [51] find no significant associations of FDI with overweight and obesity, while Sudharsanan et al. [73] find that the impact of FDI on the prevalence of diabetes is insignificant after controlling for population ageing.

The discrepancies regarding the significance of effects might be due to the differences in the data coverage (Miljkovic et al. [69] use a smaller number of countries than de Soysa and de Soysa [51] or Sudharsanan et al. [73], for example, but a longer time period) and study design (Miljkovic et al. [69], for example only find significant associations when using a quantile regression design, which is not implemented in other studies).

Although there appears to be some evidence of an association between FDI and some indicators of dietary quality, we have found no evidence linking it to underweight or undernutrition. The earlier literature analysed this issue within the debate on the "dependency versus modernization" impacts of foreign investment and Trans-national Company (TNC) penetration in developing countries. Two studies $[61,74]$ found strong negative impacts of TNC investment on per capita availability of calories and proteins in LMICs, while Jenkins and Scanlan [62] find a positive association which is small compared to the effects of domestic investment. More recent studies $[75,76]$ added some nuance to this debate, showing that the impact of FDI on nutritional indicators seems to vary depending on the sector. The former study concluded that FDI in the primary sector has tended to harm food security in LMICs through a combination of resource exploitation, labour market effects and negative environmental and demographic externalities. However, FDI in the manufacturing sector leads to modernization, technological and human capital spill-overs and increased wages, improving nutritional outcomes. The negative impact of agricultural FDI on calorie and protein intakes is corroborated by Djokoto [76] in the case of Ghana. Three studies were identified that examined explicitly the relationship between FDI and underweight, all of which failed to find any significant association for either adults $[67,68]$ or children [62].

\section{Sociocultural aspects of globalization}

Five studies analysed the impact of social components of globalization alongside economic components [51, 55-57, 69]. Social components include flows of information via television (TV), internet and telephone, interpersonal contact and cultural aspects. The first two of these studies $[55,56]$ find that globalization as a whole tends to be associated with an increase in obesity rates, and this effect is driven largely by the social component. This is consistent with findings by Miljkovic et al. [69] who find that social globalization leads to higher prevalence of obesity. Oberlander et al. [57] find that, while economic globalization is associated with a higher prevalence of diabetes and higher BMI, only social globalization is associated with increased supply of sugar and animal protein, with the results being primarily driven by increased flows of information (e.g. through internet and TV). de Soysa et al. find non-significant impacts of social globalization on the prevalence of obesity [51], in a model that controls for the economic globalization component of KOF index and the standard control variables, as well as including country and time fixed-effects.

Further research is needed in order to interpret these findings in the context of food systems and nutrition outcomes, examining the impacts of specific variables within these indices. Although these studies did not report strong multi-collinearity across the control variables, the complexity of the mechanisms involved and the potential inter-relations between the variables and indices included should be taken into account when interpreting these results.

\section{Policy and regulatory space}

Three studies analyse the nutritional impacts of political and policy changes underlying globalization processes, comparing these to the effects of economic integration processes using the political component of KOF index, as well as an Index of Economic Freedom [51]. Goryakin et al. [55] suggest that there is a positive and convex relationship between political globalization, measured by 
the KOF index, and overweight. This implies that the association is not proportional and does not tend to plateau as integration increases, but tends to be larger at higher levels of political integration. De Soysa et al. [51], on the other hand, using a larger sample, find that both political globalization measured through KOF index, and the degree of free-market capitalism, measured through the Economic Freedom Index, seem to be associated with reduced rates of child and youth obesity. Costa-i-Font et al. [56] check for the effects of political globalization as part of their sensitivity analysis, finding no significant impacts on obesity or calorie intake, although there seems to be an association with higher fat intakes.

The quantitative studies in this review offer limited evidence on the direct impact of policy and regulatory changes associated with trade and investment liberalization, suggesting some potential associations that deserve further analysis, but overall leading to mixed and inconclusive findings. The differences in results, as in other cases, can be attributed both to data coverage as well as potentially to the study design and choice of control variables. de Soysa et al. [51] use the largest country sample, while Goryakin et al. [55] include additional controls such as the Human Development Index (HDI) in all of their fixed-effects specifications, where country heterogeneity is controlled for.

\section{Socioeconomic and demographic factors as moderators of impact}

Only four articles were found to control for individual level factors [55, 65, 67, 68]. Of these, only three estimate differential associations of globalization or macroeconomic variables with nutrition outcomes in different subgroups. Two of these studies found significant differential effects across sub-groups. Nandi et al. [67], for example, find that increased FDI is associated with a $17 \%$ increase in the odds of overweight for rural men only. Neuman et al. [68] find that, although FDI is positively associated with overweight in most sub-groups, the association is negative for the wealthiest urban category, which is consistent with market segmentation practices whereby healthier products are targeted at high income consumers. de Soysa and de Soysa [51] is the only study focussing on children and youth. The authors comment that impacts on adults, included as part of their sensitivity analysis but not reported, are very similar to those obtained for individuals under the age of 19 .

\section{Discussion and interpretation}

The empirical evidence analysed in this review highlights the important role of globalization processes as drivers of dietary change and nutrition-related health outcomes. There is no agreement, however, with respect to the overall impacts of economic globalization and its components, or even the sign of these impacts, as discussed in Section Economic globalization: trade and investment. Results can be affected by the type of countries included (LMIC only [67], versus panels including both high and low income countries [69]), the population studied (children and youth [51], women only [55], adults only [56], or the overall population [73]), the choice of control variables (for example, whether the study controls for inequality, HDI or female labour participation), as well as the method chosen to control for heterogeneity (both time invariant and dynamic, [57]) and to capture non-linearities [55] and interactions across factors [72].

The studies reviewed have some limitations which should be considered when interpreting our results. Seven of the articles identified rely on average nutrient per capita availability at a country level, which has been found to be a weak indicator of important nutritional outcomes such as child underweight [62]. More generally, the use of aggregate indicators of nutrition can mask the uneven distribution of the gains of liberalization, or hide important sectoral differences, which deserve further investigation. The use of quantitative, a posteriori statistical analysis, moreover, precludes the analysis of some country-specific mechanisms and their interactions. Furthermore, we should be cautious when drawing conclusions on causality, given that these studies are based on observational data (often highly aggregated), and some of the methods used might be better suited for the analysis of broad trends and associations. Although these limitations can be addressed to a certain extent through careful study design, the results from the studies in this review should be interpreted with caution and should be understood as complementary to other types of evidence, both quantitative and qualitative.

Evidence on the associations between globalization processes on undernutrition and underweight is limited, particularly compared to the number of studies analysing overweight and obesity. There is a scarcity, of empirical studies, based on cross-country or natural experiment designs which control for confounding factors and which use individual or household level measures of dietary adequacy and nutritional status including nutrient deficiencies, underweight and stunting.

Despite these limitations, the studies reviewed, particularly when analysed together, provide relevant insights regarding different mechanisms and sub-components, their relative importance, distinctive roles and potential interactions. First, the suggestion that trade openness and FDI is likely to have played distinct roles so far in the nutrition transition. There is some recent evidence linking traded openness to reductions in underweight, $[65,67]$ and improvements in dietary adequacy and diversity [64] but not to increased prevalence of overweight or obesity 
[51, 67, 69]. FDI, meanwhile, has been found to be associated with increased prevalence of obesity and overweight in LMICs $[28,67,69,70]$, (although not diabetes, according to the study by Sudharsanan et al. [73]) but there is no clear evidence that it is associated with reductions in undernutrition. Mihalache et al. [75] and Djokoto [76] find that the impacts can depend on sectoral composition and context-specific mechanisms relating to migratory and labour market dynamics.

This pattern of association could reflect a trend towards FDI as the main vehicle for food system integration, which has been identified and described in the literature $[28,77]$. FDI can provide greater opportunities for market penetration of TFC through vertical and horizontal integration, transformation of the distribution and retail segments, effective advertisement and adaptation to local consumer tastes or 'glocalization' [78].

The lack of association between trade openness and over-nutrition could also suggest that availability and affordability of food products, per se, are not enough to lead to the changes in lifestyle and consumption patterns associated to NCDs prevalence. Direct investment, on the other hand, has the capacity to deeply transform the food sector and the wider economic system, altering consumer behaviour as part of this process (see Section Foreign direct investment).

Additionally, the (relatively scarce) evidence linking trade openness to reduced under-weight or improved dietary quality should be interpreted with caution. It is important to bear in mind that in this review we do not include outcome measures related to food prices or relative food expenditure which might be affected by trade liberalization. Short-term relative price fluctuations, however, can have important impacts on food security which might not be captured by the studies reviewed.

The apparent association between trade openness and improved nutrition outcomes, however, could reflect the impact of trade policies explicitly aimed at improving food security and mitigating the impact of international price spikes on domestic prices of staple foods. These measures include selective reductions in import protection of essential foods, sometimes coupled to public stockpiling and distribution programs [79]. Despite the controversy around the effectiveness of some of these interventions and their impacts on global price volatility [80], measures aimed at selectively lowering import barriers for food staples have been found to be successful in several LMICs $[25,79,80]$.

Policy makers can also exert control over FDI and transnational food companies, setting standards for processing, labelling, packaging and retail. Once large investors enter the market, however, food systems are rapidly and deeply transformed in ways that can be hard to control, requiring regulation at many segments along the value chain, from processing to packaging, advertising and distribution [81]. Moreover, some have argued that, as large companies become established nationally, they can constrain the space for nutrition oriented policy through lobbying and re-location threats [82].

The lack of apparent overall association between FDI and under-nutrition can be interpreted as evidence that the most disadvantaged segments of society are excluded from the potential benefits of economic growth in general, and of more efficient and modernized food systems in particular. In addition to their low purchasing power, these populations often live either in poor quality housing or slums which have little infrastructure [83], or in remote rural areas, providing few economic incentives for the establishment of supermarkets and the delivery of a variety of fresh produce.

The multi-country studies in this review generally measure aggregate flows of FDI at a national level. In terms of its association with overweight and obesity, after controlling for a range of socio-economic variables, this aggregate FDI is generally interpreted as a proxy for greater integration of food systems, and the entry of TFCs into the market [72]. While this might be a reasonable assumption in most cases, FDI has deep impacts on the productive and social structure of receiving countries that go well beyond food systems, affecting income distribution, migration patterns and lifestyles, all of which can have important implications for nutrition outcomes [75]. The detailed sectoral analysis of the impacts of FDI on nutrition deserves more attention. A combination of case studies and cross-country analysis might shed more light over complex context-specific mechanisms concerning FDI in the primary, secondary and tertiary sectors.

Another relevant finding in the literature concerns the potentially crucial role of sociocultural aspects and in particular global flows of information in explaining dietary changes. The empirical literature uses the social component of the KOF index of globalization which, among others, includes variables reflecting TV ownership, internet access, foreign films viewing, use of phones and number of McDonalds per capita. Two studies find relevant positive associations with overweight, calorie and fat consumption, which seem to dominate the effects of economic flows $[55,56]$. These results offer more than one interpretation, however. On the one hand, the access to communication technologies and foreign entertainment products can lead to increased exposure to globalized food marketing, which has been identified as a key component of food system integration. Marketing includes not only conventional advertising but also sports sponsorship and product placement in films, videos and other forms of entertainment [36, 84]. Moreover, advertising can have indirect effects 
on diets, as it increases the demand not only for the marketed brand but for the category as a whole, be it snacks, bakery products, fries or hamburgers. The variable reflecting number of McDonalds per capita is part of the "cultural proximity" sub-component of the index. In this context, this variable could potentially be interpreted as a food-specific proxy for FDI influx, and one which epitomises the subordination of the exchange of information and cultural values to economic forces. On the other hand, increased access to technology could be correlated to other changes in lifestyle, social-relational characteristics of labour and socialization, which could lead to changes in dietary patterns, as discussed in Section Interaction with socioeconomic drivers of nutrition. This is a relatively under-studied mechanism, however, and further research will be necessary in order to disentangle the potentially overlapping mechanisms connecting increased interconnectivity and information flows to changes in nutrition outcomes.

Finally, the evidence suggests that globalization processes have different impacts across sub-groups, without necessarily exhibiting a continuous gradient. This is consistent with the dynamics of market segmentation, which tends to create divergent dietary patterns within countries, with healthier products being targeted towards wealthy urban consumers, while lower income groups become the target consumers for calorie dense "junk foods" [6].

The existence of important differences in impact across groups can also be a product of interactions between mechanisms, which either compensate or enhance each other's effects. For example, FDI might increase the access to unhealthy food commodities, but associated income growth and increased access to information might compensate by promoting health-seeking behaviour. Conversely, longer working hours or reduced time available for cooking might exacerbate the impacts of changes in food environments. Further analysis of group-specific impacts of trade and investment policies can be useful when it comes to developing more effective policy interventions.

\section{Conclusion and implications for policy and research}

Our results indicate that, overall, globalization processes and the trade and investment policies underpinning them have so far played an important role in driving changes in the nutrition status of populations in high, middle and low-income countries. Empirical literature provides, however, a nuanced view of the impact of globalization on nutrition, indicating that different processes and sub-components have different effects. In particular, trade openness contributes to shifts in dietary patterns, increasing dietary diversity and availability of cheap calories and fats and, on average, reducing under-nutrition. However, trade openness is not sufficient, per se, to explain the increases in obesity and overweight. These seem to be more associated to FDI and global flows of information in LMIC, including food marketing and advertisement.

Moreover, sociocultural aspects and particularly information flows seem to have an important impact on dietary patterns, overweight, obesity and consumption of calories and fats, even dominating the effect of trade and investment flows. This could reflect the impacts of exposure to globalized marketing, or it could reflect other lifestyle changes associated with the use of new communications technologies.

The studies reviewed support the view, suggested by others $[12,56]$ that neither overall protectionism nor unregulated liberalization are likely to reduce malnutrition, making adequate monitoring and intervention a necessity to avoid negative impacts of globalization processes on nutrition. In addition, our results suggest that governments do not necessarily face a trade-off in dealing with the double-burden of malnutrition (liberalize, and reduce under-nutrition, but face increases in over-nutrition and chronic disease, or protect against the latter, at the risk of increasing food insecurity). Rather, governments can in principle play an important role in prioritising food security through nutrition-sensitive trade policy, while simultaneously controlling and regulating foreign investment and marketing in the food sector, in order to avoid the creation of obesogenic environments. In this sense, the potentially constraining impacts of trade agreements on the policy space to pursue public health objectives have been identified as an important pathway for trade liberalization impacts on nutrition, which remains relatively unexplored in the quantitative literature [12]. Furthermore, the existence of significant differences in impacts across population sub-groups, where the most vulnerable populations tend to be affected disproportionately, highlight the need to reduce inequalities in access to food, and to develop targeted policies which can address the needs of those groups which might be most vulnerable to the impacts of globalization.

Given the complexity of the topic and the high susceptibility to bias, thorough and transparent sensitivity analysis regarding outcome measures, control variables and study design is important in order to advance the debate and improve comparability across studies. Although different approaches can provide complementary evidence, more studies are needed that use natural experiments or other methods to control for confounding and reduce bias. The roles of sociocultural, lifestyle and political aspects of globalization in the nutrition transition are relatively understudied in the quantitative literature and might be fruitful areas of research. Analyses based on 
overall indices of globalization can provide relevant insights but are often hard to interpret [85]. As suggested in recent studies [51], more evidence is needed on the impact of specific sub-components of wider processes of liberalization, including sector-specific FDI flows or different types of trade barrier. Further research on this topic should also attempt to incorporate measures of stunting, wasting and micronutrient malnutrition. Perhaps more importantly, research is needed to improve the current understanding of differential impacts of globalization and liberalization processes across sub-groups of population, in order to identify potentially vulnerable groups.

\section{Endnotes}

${ }^{1}$ See Dreher et al. (2006) [43] for a detailed description of KOF index of globalization. The economic component includes flows of international goods, services, investment and capital, as well as restrictions, such as tariffs or other taxes on international trade as well as hidden import barriers (in the form or regulations and standards, for example). The political component includes number of embassies, membership in international organizations and participation in "UN security council" meetings. The social component includes measures of flows of information (through internet, television, newspaper and other channels), cultural proximity and personal contact (including measures such as number of foreign residents, tourism or costs of a call to the US). The different components and sub-components of the index and their potential interpretation in the context of our study will be further discussed in the Results section.

${ }^{2}$ https://www.wto.org/

${ }^{3}$ For more detailed information see the WTO register of regional and bilateral trade agreements as notified to the organization https://www.wto.org/english/tratop_e/ region_e/regfac_e.htm.

\section{Additional files}

Additional file 1: Search strategy. Contains the search strategy for the review. (DOCX $17 \mathrm{~kb})$

Additional file 2: Type of evidence. Contains assessment criteria. (DOCX $12 \mathrm{~kb})$

\section{Acknowledgements}

Not applicable.

\section{Funding}

Soledad Cuevas received doctoral funding from the Leverhulme Trust. The funders have not been involved in or influenced the research process at any stage.

\section{Availability of data and materials}

The search strategy and document flow diagram are included as supporting data.

\section{Authors' contributions}

All authors contributed to the design of the study and the final document. SC carried out the search, analysed the documents and wrote the first draft of the article. HW and LC replicated the search and article screening. All authors were involved in the conception of the research, revisions and editing of the article. All authors read and approved the final manuscript.

Ethics approval and consent to participate

This study uses publicly available secondary data and did not require ethics approval.

\section{Consent for publication}

Not applicable.

\section{Competing interests}

The authors declare that they have no competing interests.

\section{Publisher's Note}

Springer Nature remains neutral with regard to jurisdictional claims in published maps and institutional affiliations.

\section{Author details}

${ }^{1}$ Department of Global Health and Development, London School of Hygiene and Tropical Medicine, Tavistock Place, London WC1H 9SH, UK. ${ }^{2}$ Leverhulme Centre for Integrate Research on Agriculture and Health, 36 Gordon Square, London WC1H OPD, UK. ${ }^{3}$ University of Exeter, Stocker Rd, Exeter EX4 4PY, UK.

${ }^{4}$ SOAS, University of London, Bloomsbury, London WC1H OXG, UK.

Received: 23 August 2018 Accepted: 4 February 2019

Published online: 20 February 2019

\section{References}

1. World Bank. World Bank open data [Internet]. [cited 2017 Apr 27]. Available from: http://data.worldbank.org/.

2. Labonté R, Schrecker T. social determinants of health: introduction and methodological background (part 1 of 3). Glob Health. 2007;3(1):5.

3. Labonte R, Mohindra KS, Lencucha R. Framing international trade and chronic disease. Glob Health. 2011;7.

4. Blouin C, Chopra M, van der Hoeven R. Trade and social determinants of health. Lancet. 2009:373(9662):502-7.

5. Walls $\mathrm{H}$, Baker $\mathrm{P}$, Parkhurst J. Addressing trade policy as a macro-structural determinant of health: the role of institutions and ideas. Glob Soc Policy. 2018;18(1):94-101.

6. Hawkes C. Uneven dietary development: Linking the policies and processes of globalization with the nutrition transition, obesity and diet-related chronic diseases. Glob Health [Internet]. 2006;2.

7. Popkin BM. Technology, transport, globalization and the nutrition transition food policy. Food Policy. 2006;31(6):554-69.

8. Alwan A. Global status report on noncommunicable diseases 2010. World Health Organization; 2011

9. Pinstrup-Andersen P. Agricultural research and policy for better health and nutrition in developing countries: a food systems approach. Agric Econ. 2007:37:187-98.

10. Panagariya A. Trade and food security: Conceptualizing the linkages. In Citeseer. 2002:11-2.

11. Thomas HC. Trade reforms and food security: country case studies and synthesis. Food \& Agriculture Org.; 2006.

12. Friel S, Hattersley L, Snowdon W, Thow A-M, Lobstein T, Sanders D, et al. Monitoring the impacts of trade agreements on food environments. Obes Rev. 2013;14(1, SI):120-34.

13. Thow AM. Trade liberalisation and the nutrition transition: mapping the pathways for public health nutritionists. Public Health Nutr. 2009;12(11):2150-8.

14. McCorriston S, Hemming DJ, Lamontagne-Godwin JD, Parr M, Osborn J, Roberts PD. What is the evidence of the impact of agricultural trade liberalisation on food security in developing countries. Syst Rev Lond EPPI Cent Univ Lond. 2013;

15. Baker $P$, Kay A, Walls $H$. Trade and investment liberalization and Asia's noncommunicable disease epidemic: a synthesis of data and existing literature. Glob Health. 2014;12:10. 
16. Barlow P, McKee M, Basu S, Stuckler D. The health impact of trade and investment agreements: a quantitative systematic review and network co-citation analysis. Glob Health. 2017:8:13.

17. Hagen-Zanker J, Mallett R. How to do a rigorous, evidence-focused literature review in international development. 2013 [cited 2017 May 14].

18. Thow AM, Kadiyala S, Khandelwal S, Menon P, Downs S, Reddy KS. Toward food policy for the dual burden of malnutrition an exploratory policy space analysis in India. Food Nutr Bull. 2016;0379572116653863.

19. Walls HL, Kadiyala S, Smith RD. Research and policy for addressing malnutrition in all its forms. Obes Silver Spring Md. 2016:24(10):2032-2.

20. WHO. WHO Malnutrition fact sheet [Internet]. World Health Organization. 2018 [cited 2019 Oct 1]. Available from: https://www.who.int/news-room/ fact-sheets/detail/malnutrition.

21. Jenkins R. Globalization, production, employment and poverty: debates and evidence. J Int Dev. 2004;16(1):1-12.

22. Woodward D, Drager N, Beaglehole R, Lipson D. Globalization and health: a framework for analysis and action. Bull World Health Organ. 2001;79(9):875-81.

23. Ogundari $\mathrm{K}$, Ito $\mathrm{S}$. Convergence and determinants of change in nutrient supply evidence from sub-Saharan African countries. Br Food J. 2015;117(12):2880-98.

24. Khoury CK, Bjorkman AD, Dempewolf H, Ramirez-Villegas J, Guarino L, Jarvis A, et al. Increasing homogeneity in global food supplies and the implications for food security. Proc Natl Acad Sci. 2014;111(11):4001-6.

25. Haggblade S. Enhancing African food security through improved regional Marketing Systems for Food Staples. Policy Res Agenda Common Mark East South Afr COMESA Mich State Univ East Lansing 2008.

26. Huang S. Global trade patterns in fruits and vegetables. 2004.

27. Thow AM, Swinburn B, Colagiuri S, Diligolevu M, Quested C, Vivili P, et al. Trade and food policy: case studies from three Pacific Island countries. Food Policy. 2010;35(6):556-64.

28. Baker P, Friel S, Schram A, Labonte R. Trade and investment liberalization, food systems change and highly processed food consumption: a natural experiment contrasting the soft-drink markets of Peru and Bolivia. Glob Health. 2016;2:12.

29. Jacks DS, O'Rourke KH, Williamson JG. Commodity price volatility and world market integration since 1700. Rev Econ Stat. 2011;93(3):800-13.

30. Drewnowski A, Hanks AS, Smith TG. International trade, food and diet costs, and the global obesity epidemic. Trade Food Diet Health Perspect Policy Options. 2010:77-90

31. Smith RD. Foreign direct investment and trade in health services: a review of the literature. Soc Sci Med. 2004;59(11):2313-23.

32. Stuckler D, Nestle M. Big food, food systems, and global health. PLoS Med. 2012;9(6):e1001242.

33. Dixon J, Omwega AM, Friel S, Burns C, Donati K, Carlisle R. The health equity dimensions of urban food systems. J Urban Health. 2007;84(1):118-29.

34. Monteiro CA, Levy RB, Claro RM, de Castro IRR, Cannon G. Increasing consumption of ultra-processed foods and likely impact on human health: evidence from Brazil. Public Health Nutr. 2010;14(1):5-13.

35. McChesney RW, Schiller D. The political economy of international communications: foundations for the emerging global debate about media ownership and regulation. Geneva: United Nations Research Institute for Social Development; 2003.

36. Hawkes C. Marketing activities of global soft drink and fast food companies in emerging markets: a review. Glob Diets Noncommunicable Dis. 2002:1-78.

37. Baldwin RE. 21st century regionalism: filling the gap between 21 st century trade and 20th century trade rules. 2011.

38. Walls HL, Smith RD, Drahos P. Improving regulatory capacity to manage risks associated with trade agreements. Glob Health. 2015;11(1):14.

39. Friel $\mathrm{S}$, Gleeson D, Thow A-M, Labonte $\mathrm{R}$, Stuckler D, Kay A, et al. A new generation of trade policy: potential risks to diet-related health from the trans pacific partnership agreement. Glob Health. 2013;16:9.

40. Walls HL, Hanefeld J, Smith RD. The trans-Pacific partnership: should we" fear the fear"?: comment on" the trans-Pacific partnership: is it everything we feared for health?". Int J Health Policy Manag. 2017;6(6):353.

41. Thow AM, Snowdon W, Labonté R, Gleeson D, Stuckler D, Hattersley L, et al. Will the next generation of preferential trade and investment agreements undermine prevention of noncommunicable diseases? A prospective policy analysis of the trans Pacific partnership agreement. Health Policy. 2015;119(1):88-96

42. Barlow P, Labonte R, McKee M, Stuckler D. Trade challenges at the World Trade Organization to national noncommunicable disease prevention policies: a thematic document analysis of trade and health policy space. PLOS Med. 2018;15(6):e1002590.
43. Dreher A. Does globalization affect growth? Evidence from a new index of globalization. Appl Econ. 2006;38(10):1091-110.

44. Berg A, Krueger AO. Trade, growth, and poverty: A selective survey. In 2003. p. 47-89.

45. Dreher A, Gaston N. Has globalization increased inequality? Rev Int Econ. 2008;16(3):516-36.

46. Kanbur R. Globalization and inequality. Handb Income Distrib. 2015;2:1845-81.

47. Tiffen M. Transition in sub-Saharan Africa: agriculture, urbanization and income growth. World Dev. 2003;31(8):1343-66.

48. Aide TM, Grau HR. Globalization, migration, and Latin American ecosystems. Science. 2004;305(5692):1915-6.

49. Singh A, Zammit A. Labour standards and the 'race to the bottom': rethinking globalization and workers' rights from developmental and solidaristic perspectives. Oxf Rev Econ Policy. 2004:20(1):85-104.

50. Huneault L, Mathieu M, Tremblay A. Globalization and modernization: an obesogenic combination. Obes Rev. 2011;12(5).

51. de Soysa I, de Soysa AK. Do Globalization \& Free Markets Drive Obesity Among Children and Youth? An Empirical Analysis, 1990-2013. Int Interact. 2017; (just-accepted).

52. Mallett R, Hagen-Zanker J, Slater R, Duvendack M. The benefits and challenges of using systematic reviews in international development research. J Dev Eff. 2012:4(3):445-55.

53. O'Mara-Eves A, Brunton G, McDaid D, Kavanagh J, Oliver S, Thomas J. Techniques for identifying cross-disciplinary and 'hard-to-detect'evidence for systematic review. Res Synth Methods. 2014;5(1):50-9.

54. Wong G, Greenhalgh T, Westhorp G, Buckingham J, Pawson R. RAMESES publication standards: realist syntheses. BMC Med. 2013;11(1):21.

55. Goryakin Y, Lobstein T, James WPT, Suhrcke M. The impact of economic, political and social globalization on overweight and obesity in the 56 low and middle income countries. Soc Sci Med. 2015;133(SI):67-76.

56. Costa-Font J, Mas N. 'Globesity'? The effects of globalization on obesity and caloric intake. Food Policy. 2016;64:121-32.

57. Oberländer L, Disdier A-C, Etilé F. Globalisation and national trends in nutrition and health-a grouped fixed-effects approach to inter-country heterogeneity. 2016.

58. de Vogli R, Kouvonen A, Elovainio M, Marmot M. Economic globalization, inequality and body mass index: a cross-national analysis of 127 countries. Crit Public Health. 2014;24(1):7-21.

59. Schram A, Labonte R, Sanders D. Urbanization and international Trade and investment policies as determinants of noncommunicable diseases in sub-Saharan Africa. Prog Cardiovasc Dis. 2013;56(3):281-301.

60. Gacitua EA, Bello R. Agricultural exports, food production, and food security in Latin America. Rural Sociol. 1991;56(3):391-405.

61. Wimberley DW, Bello R. Effects of foreign investment, exports, and economic growth on third world food consumption. Soc Forces. 1992:70(4):895-921.

62. Jenkins JC, Scanlan SJ. Food security in less developed countries, 1970 to. Am Sociol Rev. 1990;2001:718-44.

63. Bezuneh $M$, Yiheyis Z. Has trade liberalization improved food availability in developing countries? An empirical analysis. J Econ Dev. 2014:39(1):63.

64. Dithmer J, Abdulai A. Does trade openness contribute to food security? A dynamic panel analysis. Food Policy. 2017;69:218-30.

65. Del Ninno C, Dorosh P, Smith L. Public policy, markets and household coping strategies in Bangladesh: avoiding a food security crisis following the 1998 floods. World Dev. 2003;31(7):1221-38.

66. Zakaria M, Xi J. Food security in south Asian countries: 1972 to 2013. Afr Asian Stud. 2014;13(4):479-503.

67. Nandi A, Sweet E, Kawachi I, Heymann J, Galea S. Associations between macrolevel economic factors and weight distributions in low- and middleincome countries: a multilevel analysis of 200000 adults in 40 countries. Am J Public Health. 2014 Feb;104(2):E162-71.

68. Neuman M, Kawachi I, Gortmaker S, Subramanian SV. National Economic Development and disparities in body mass index: a cross-sectional study of data from 38 countries. PLoS One. 2014;11:9(6).

69. Miljkovic D, Shaik S, Miranda S, Barabanov N, Liogier A. Globalisation and obesity. World Econ. 2015 Aug;38(8):1278-94.

70. Schram A, Labonte R, Baker P, Friel S, Reeves A, Stuckler D. The role of trade and investment liberalization in the sugar-sweetened carbonated beverages market: a natural experiment contrasting Vietnam and the Philippines. Glob Health. 2015 Oct;11(41). 
71. Schneider MB, Benjamin HJ. Sports drinks and energy drinks for children and adolescents: are they appropriate? Pediatrics. 2011;127(6):1182-9.

72. Stuckler D, McKee M, Ebrahim S, Basu S. Manufacturing epidemics: the role of global producers in increased consumption of unhealthy commodities including processed foods, alcohol, and tobacco. PLoS Med. 2012;9(6): e1001235.

73. Sudharsanan N, Ali MK, Mehta NK, Narayan KMV. Population aging, macroeconomic changes, and global diabetes prevalence, 1990-2008. Popul Health Metrics. 2015;5:13.

74. Wimberley DW. Transnational corporate investment and food the third world: a cross-National Analysis. Rural Sociol. 1991;56(3):406-31.

75. Mihalache-O'keef A, Li Q. Modernization vs. dependency revisited: effects of foreign direct investment on food security in less developed Countries1. Int Stud Q. 2011;55(1):71-93.

76. Djokoto JG. Effects of foreign direct investment inflows into agriculture on food security in Ghana. J Econ Sustain Dev. 2012;3(2):81-92.

77. Hawkes C. Uneven dietary development: linking the policies and processes of globalization with the nutrition transition, obesity and diet-related chronic diseases. Glob Health. 2006;2.

78. Roudometof V. Transnationalism, cosmopolitanism and glocalization. Curr Sociol. 2005;53(1):113-35.

79. Gillson I, Fouad A. Trade policy and food security: improving access to food in developing countries in the wake of high world prices. Washington, DC: World Bank; 2015.

80. Anderson K, Ivanic M, Martin WJ. Food price spikes, price insulation, and poverty. In: The economics of food price volatility. University of Chicago Press; 2014. p. 311-39.

81. Hawkes C. Identifying innovative interventions to promote healthy eating using consumption-oriented food supply chain analysis. J Hunger Environ Nutr. 2009; $4(3-4): 336-56$

82. Brownell $\mathrm{KD}$, Warner KE. The perils of ignoring history: big tobacco played dirty and millions died. How similar is big food? Milbank Q. 2009:87(1):259-94.

83. Ruel MT, Garrett JL, Haddad L. Rapid urbanization and the challenges of obtaining food and nutrition security. In: Nutrition and health in developing countries. Springer; 2008. p. 639-656.

84. Schmitt NM, Wagner N, Kirch W. Consumers' freedom of choice-advertising aimed at children, product placement, and food labeling. J Public Health. 2007;15(1):57-62

85. Smith R. Measuring the globalization of health services: a possible index of openness of country health sectors to trade. Health Econ Policy Law. 2006;1(4):323.

Ready to submit your research? Choose BMC and benefit from:

- fast, convenient online submission

- thorough peer review by experienced researchers in your field

- rapid publication on acceptance

- support for research data, including large and complex data types

- gold Open Access which fosters wider collaboration and increased citations

- maximum visibility for your research: over $100 \mathrm{M}$ website views per year

At $\mathrm{BMC}$, research is always in progress.

Learn more biomedcentral.com/submissions 